\title{
Leucine Crystal Measurement
}

National Cancer Institute

\section{Source}

National Cancer Institute. Leucine Crystal Measurement. NCI Thesaurus. Code C74680.

The determination of the amount of leucine crystals present in a sample. 